\title{
Research of Sanatorium and Resort Activity in the Context of Scientific Provisions of Health Economics and the Concept of Human Capital
}

\author{
Olesya Kharitonenko*
}

\author{
Ural State University of Economics, Ekaterinburg, Russia \\ *Corresponding author. Email: rime@usue.ru
}

\begin{abstract}
The article supplements the theoretical foundation of the scientific paradigm of the study of sanatorium and resort activity at the regional (local) level, based on a multidisciplinary approach combining a set of fundamental provisions of health economics and the concept of human capital, which made it possible to propose and disclose a logical model of the study of sanatorium and resort activity in time and space. The author reveals the key provisions of the new scientific direction "health economics" and shows its scientific roots dating back to the research of the XVII century. The article presents the evolution of the concept of human capital and its significance for the study of sanatorium and resort activities both at the national and regional (local) level. Based on the provisions of the new emerging scientific field of health economics, as well as the concept of human capital, the study emphasizes the increasing importance in modern society, in the structure of its economy, and in such economic activities as health care and spa that are part of it.
\end{abstract}

Keywords: sanatorium and resort activity", health economics, human capital concept, theoretical background of sanatorium and resort activity research.

\section{INTRODUCTION}

In modern conditions of economic and social development, significant deterioration of the sanitary and epidemiological situation, a special type of economic activity - sanatorium and resort activity is becoming increasingly important. The coronavirus pandemic (COVID-19) has brought to the forefront of theoretical and practical developments the problems of the population protection, strengthening and restoring their health and building up health capital. Sanatorium and resort activities, which are an integral component of the country's healthcare system, are of great importance in solving these problems.

Economics considers sanatorium and resort activity as a service related to the satisfaction of specific basic human needs in strengthening, restoring and maintaining health.

For in-depth study of sanatorium and resort activity, identification and substantiation of its fundamental characteristics, it is necessary to use a scientific paradigm.
The scientific paradigm of the research of sanatorium and resort activity is being developed.

The analysis of the scientific literature allows to assert that the paradigmatic attitudes of the study of the peculiarities of the development and territorial organization of sanatorium and resort activities are based on the interdisciplinary foundation of the provisions of the health economy, the concept of human capital, the quality of life of the population, the theory of services and theories of regional (local) economic development.

We believe that an important theoretical basis for the study of sanatorium and resort activities and the knowledge of regional aspects of its functioning, transformation and development is represented by a new emerging scientific field - the economics of health, the origin of which is attributed to the end of the XX century $[1,2,3,4]$ and the concept of human capital $[5,6,7,8]$.

\section{MATERIALS AND METHODS}

The ideologist of the new field in economics, academician Okrepilov V.V., reveals its content as 
follows: "The health economy considers public and individual health as one of the components of economic growth, and consequently, of sustainable development of the state, which can and should be managed, since the better the state of public health is, the higher the pace of socio-economic development of the state becomes" [4, p. 34].

The decline in the health indicators of the population of the country, its regions and municipalities entails a reduction in production volumes, its disorganization, and causes additional costs due to the need to fulfill state obligations to pay sick leave, pension contributions, as well as to maintain social infrastructure facilities.

The surge of interest of science in research conducted within the framework of the health economy was caused by the coronavirus pandemic (COVID-19) that broke out at the end of 2019, which caused enormous damage to the global, national and regional economies, made significant adjustments to the prevailing positive global, Russian and regional trends in the quality of life of the population and significantly reduced the human capital of the countries and their regions [9].

Economic science has to make reasonable conclusions on the results of the coronavirus pandemic. According to preliminary estimates of the Ministry of Foreign Affairs of Russia, the losses of the world economy as a result of the coronavirus pandemic are estimated at more than $\$ 3.5$ trillion, which is twice as much the damage from the economic crisis of 2008. Huge losses are caused by the shutdown of enterprises and institutions in countries with a high percentage of COVID cases, the disruption of international operations, and the closure of state borders.

According to Rosstat, in 2020, the resident population of Russia decreased by 577.6 thousand people (from 146.75 million people to 146.17 million people), breaking down all the positive trends of the last fifteen years. Life expectancy in Russia by the end of 2020 decreased to 71.1 years against 73.3 years in 2019 , which is observed for the first time since 2003. This negative trend is due to an increase in mortality in Russia, which amounted to 323.8 thousand people compared to 2019 . According to experts, Russia will be able to return to the level of 2019 no earlier than in 2024.

A decrease in life expectancy against the background of coronavirus is observed in other countries too. So, in the USA, this indicator in the first half of 2020 decreased by one year (from 78.8 to 77.8 years) - this is the largest decrease since 1943 .

The global threat has confirmed the need and importance of an effective state policy in the field of public health, which increases the significance of domestic health care and its important component sanatorium and resort activities.
The problems of dependence of economic dynamics and human health were considered in the scientific works of foreign and Russian classical economic scientists.

It should be noted that back in the XVII century, the English economist W. Petty proved the existence of a close feedback between the economic indicators of the country's development, economic losses and the scale of epidemics, and human mortality [10]. In his research, the scientist represents the economic importance of a person. According to W. Petty, the main tool for creating wealth is labor, the basis of which is a person. It is complemented by land and capital, which represent the material base of prosperity.

In the XVIII century the founder of economic theory as a science, A. Smith described the relationship between health and labor productivity: "There can be no doubt ... that people generally cannot work more with poor nutrition, depressed mood and frequent illnesses than with abundant nutrition, cheerful mood and good health. It should be noted that years of high prices are usually years of illness and increased mortality for the common people, which cannot but cause a decrease in labor productivity" [11, p. 76].

English economist, one of the founders of the neoclassical trend in economics A. Marshall considers health as the basis for productivity and the creation of material goods. Revealing a natural connection between human health, labor organization and income, health was considered by him as a resource factor affecting human potential [12].

In the final part of the fifth chapter "The health and strength of the population" of his fundamental work "Principles of Economics", A. Marshall draws an important conclusion from the viewpoint of a newly developed scientific field of "health economics" concerning sanatorium and resort activities: "the progress of knowledge, especially medical science, the everincreasing activity and wisdom of Government in all matters related to health, and the increase of material wealth, - all tend to lessen mortality, and to increase health and strength, and to lengthen life" [12].

Modern scientific research provides evidence of a close relationship between the loss of the population's ability to work as a result of diseases, recognition of disability or death and a key macroeconomic indicator the volume of gross domestic product. In particular, academician V.V. Okrepilov notes: "Due to temporary disability, the state loses about $0.3 \%$ of GDP, and due to premature death $-17 \%$ of GDP. That is, the figures of losses are very significant and the urgency of the problem of preserving the health of the population is very high" [4, p. 34]. In turn, an increase in the average life expectancy of the population by one year can lead to an increase in GDP by $4 \%$. 
Based on the above, it can be argued that the main indicator of public health - life expectancy - is in proportion to the level of GDP and government expenses in the health sector.

Academician Aganbegyan A.G. in his research notes: "Every year in Russia, more than 2 million people die due to neglect of their health; unfavorable conditions; low level of domestic medicine, unavailability of effective medical care for a significant part of the population... The high percentage of deaths (up to $30 \%$ ) among people of working age is particularly worrying (in Western Europe it is about 10\%) ... People in Russia die from diseases 12 years earlier than in Western Europe: men die 16 earlier, women -9 years" [13, p. 5-6].

In this regard, the importance of health research by economic scientists increases: "Both the value and the importance of health are much greater than such familiar types of resources as forest, coal, gas, oil... All this gives us grounds to consider health not only from the point of view of medicine or sociology, but also from the point of view of economics and to talk about the emergence of a new field in science - the economics of health" [4, p. 34].

Thus, within the framework of the concept of health economics, theoretical and methodological approaches to the economic interpretation of public health and the effectiveness of investments in health are substantiated.

\section{RESULTS AND DISCUSSION}

The study of human health and its economic component is closely related to the concept of human capital proposed in the second half of the XX century by American economists, Nobel Prize laureates T. Schultz [5] and G. Becker [6].

T. Schultz first used the term "human capital", which he interpreted as "all human abilities - innate or acquired. Attributes ... that are valuable and can be supplemented with appropriate investments ..." [5, p. 62].

This idea was developed by G. Becker, justifying the effectiveness of investments in human capital and formulating an economic approach to human behavior. He adds a component of health to the measurement of human capital, interpreting it as "knowledge, information, ideas, skills and people's health" [6, p. 3]. G. Becker, in addition to the value of health for an individual, describes the impact of health on the accumulation period and the use of education and experience - as components of human capital [7, p. 92].

Modern encyclopedia articles interpret human capital as follows: "assessment of the potential ability to generate income embodied in an individual. Human capital includes innate abilities, as well as education and acquired qualifications that contribute to increasing labor productivity" [14, p. 188]. When defining human capital, we usually mean the cost created as a result of the costs of training, education, and health promotion.

Developing the model of investments in health proposed by G. Becker, the American economist M. Grossman investigated the influence of the level of investments in health on various aspects of human life, assuming that a higher level of health provides an opportunity for more complete satisfaction of needs.

In 1972, M. Grossman, using the theory of human capital by G. Becker and T. Schultz, introduced the term "health capital" into the scientific sphere [8], the provision of which is closely related to the activities of medical institutions and the health care system, to which consumers resort to receive specific medical services in order to improve their health and cure diseases. Health is considered by scientists in two meanings: as a consumer good that has a certain demand, and as a means of making a profit. Being an object of investment, health is a part of human capital.

According to M. Grossman, health is a durable commodity necessary for the formation and development of human capital. In M. Grossman's model, human behavior corresponds to the behavior of a rational investor who faces a choice: what is he willing to sacrifice at present to improve his health and increase life expectancy in the future. In this case, the amount of investment of each person depends on his long-term preferences.

The American economist K. Arrow described the distinctive features of health in comparison with other goods and services, emphasizing the fact that for an individual, health as an object of demand has the characteristics of both consumer goods (in this case, health is considered as a source of utility) and economic (the impact of health on labor activity through the duration of job search, characteristics of the place of work, the amount of total income representing the economic return on health) [15].

The capital of health in modern scientific research is understood as investments in a person necessary for the formation, maintenance and improvement of his health and working capacity $[16,17]$. Consumers, investing resources in medical services, drug therapy, environmentally friendly food, as well as giving up tobacco and alcohol, thereby invest in health capital accumulating it.

\section{CONCLUSION}

Summing up the above, we will present our own conclusions, which are an increment of scientific knowledge in matters of research of sanatorium and resort activities.

1. The scientific paradigm of the study of sanatorium and resort activities at the regional and municipal levels 
is formed on the provisions of the following main theoretical platforms: health economics, the concept of human capital, the concept of quality of life, the theory of services and the theory of regional economic development, which create a logical model for the study of sanatorium and resort activities in the economic space of the region.

2. Based on the provisions of the new emerging scientific field of health economics, as well as the concept of human capital and the quality of life of the population, the author emphasizes the increasing importance of such economic activities as healthcare and spa activities in modern society in general and in the structure of its economy, in particular.

Sanatorium and resort activity as a special type of economic activity is aimed at strengthening the individual and public health of the population of the country and its regions, which is an important economic resource that provides economic growth rates, dynamics of socio-economic development of the national, regional and municipal economy.

Sanatorium and resort activities are aimed at strengthening human health, which is an important social resource that forms human capital, the quality of human resources, the quality of life of the population of the state as a whole and its constituent regions and municipalities.

The importance of sanatorium-resort activity is enhanced due to the fact that it is focused on the preferential use of unique, natural healing resources and factors, which is in line with the emerging scientific field known as "green economy".

3. When organizing sanatorium and resort activities at the national, regional and municipal levels, it is necessary to take into account the economic features of health: health is a limited good, a partially replenished resource, an immaterial resource, a consumer good and a capital resource.

\section{REFERENCES}

[1] A.J. Culyer, J.P. Newhouse, Handbook of Health Economics. Elsevier B.V., 2000.

[2] V.R. Fuchs, The future of health economics. Journal of Health Economics 19 (2000) pp. 145-151. DOI: https://doi.org/10.1016/s0167-6296(99)00033-8.

[3] S. Folland, A.C. Goodman, M. Stano The Economics of Health and Health Care. Pearson, 2010.

[4] V.V. Okrepilov, Development of the health economy to improve the quality of life. Economic and social changes: facts, trends, forecast 5(23) (2012) pp. 33-47.
[5] T.W. Schultz, Investment in Human Capital: The Role of Education and of Research. The Free Press, 1971.

[6] G.S. Becker, Human Capital: A Theoretical and Empirical Analysis with Special Reference to Education. Univer-sity of Chicago Press, 1993.

[7] G.S. Becker, Human behavior: an economic approach. Selected works on economic theory: trans. from English. Higher School of Economics, 2003.

[8] M. Grossman, On the Concept of Health Capital and the Demand for Health. Journal of Political Economy 80(2) (1972) pp. 223-255.

[9] K. Schwab, T. Malleret, COVID-19: The Great Reset. Geneva. Forum Publishing, 2020. http://reparti.free.fr/schwab2020.pdf.

[10] W. Petty, The political anatomy of Ireland; to which is added Verbum sapienti, 1691.

[11] A. Smith, Research on the nature and causes of the wealth of nations. Inquiry into the nature and causes of the wealth of nations. State Social Economy. State Social Economy publishing house, 1935.

[12] A. Marshall, Principles of Economics. Book 1 Bizneskom, 2010.

[13] A.G. Aganbegyan, How to live and stay healthy for a long time. IVF 10(448) (2011) pp. 5-12.

[14] E.E. Rumyantseva, New Economic Encyclopedia. INFRA-M, 2005

[15] K.J. Arrow Uncertainty and the welfare economics of medical care. American Economic Review 53 (1963) pp. 941-973.

[16] E.V. Bazueva, Human capital of the Perm Region: gender features of implementation. Economy of the region 2(22) (2010) pp. 46-59.

[17] D.I. Aslanov System concepts of health as the main component of human capital. Fundamental research 12(1) (2011) pp. 202-206. 